\title{
Geomorphological And Sedimentary Records of Late Quaternary Activities of Qiaojia-Jinyang Segment of Lianfeng Fault Zone, Southwest China
}

\section{Youpeng Wang}

National Institute of Natural Hazards: Institute of Crustal Dynamics

Dewen Li ( $\square$ lidewen@263.net)

National Institute of Natural Hazards: Institute of Crustal Dynamics https://orcid.org/0000-0002-92822954

\section{Research Article}

Keywords: seismicity, Lianfeng Fault Zone, sand vein, river terrace, active fault

Posted Date: September 8th, 2021

DOl: https://doi.org/10.21203/rs.3.rs-793347/v1

License: (a) (1) This work is licensed under a Creative Commons Attribution 4.0 International License.

Read Full License

Version of Record: A version of this preprint was published at Environmental Earth Sciences on February 25th, 2022. See the published version at https://doi.org/10.1007/s12665-022-10262-7. 


\section{Abstract}

Lianfeng Fault Zone (LFZ) in Southwest China has great significance for understanding the seismogenic environment, but its activity is still poor constrains. The Qiaojia-Jinyang segment (QJS) of LFZ intersects with Jinsha River; Here well developed river terraces provide a potential Spatiotemporal constrains for faulting. Based on investigation of the terrace deposits along river, this paper makes a detailed logging and dating of the faulting and liquefaction of QJS. Combined previous data, the spatiotemporal sequence of the Late Quaternary river terraces in the area was redetermined. It is considered that the first and second grade river terraces at QJS ( 10-20m and 60-70m, respectively, above the local river level) are roughly developed in the middle Holocene and the late Late Pleistocene, indicating that the valley along QJS was strongly undercut since the Late Pleistocene. Based on the analysis of the morphological characteristics, spatial distribution, material composition and intersecting relationship between the sand veins and the layers, the cause of the ground motions is preliminarily determined, which indicates the strong seismic activity of the LFZ during the Quaternary. Combined with the faulting characteristics within the profiles of terrace deposits and the dating data of the overlying strata, it is considered that the LFZ is active at least at QJS, and the latest active time is not earlier than the early-middle Holocene. These understandings provide a clear geological evidences for the seismicity assessment at LFZ, and help to the understanding of regional tectonic environment and the prevention of earthquake disasters.

\section{Introduction}

Fault activity is an basis for understanding regional seismotectonic environment and establishing seismotectonic model. As the Indian plate pushes northward, the Tibetan Plateau becomes the largest and highest plateau in the world(Ruddiman 1997), the internal material of the plateau continued to extrude laterally in the north, east and southeast directions(Zhang et al. 2018), Due to the influence of Sichuan basin, the southeast margin of the plateau formed(Wen et al. 2013), such as Sichuan-Yunnan block and Daliangshan sub-block, which became one of the most concentrated earthquakes in Chinese mainland(Chang et al. 2014). Lianfeng Fault Zone (LFZ) is located in the border of Sichuan and Yunnan province, which is the boundary between Daliangshan sub-block and relatively stable South China block. Some literatures believed that there is a "seismic-gap"(Davies et al. 1981; Gaudemer et al. 1995; Perez and Jacob 1980; Sykes 1971; Wen et al. 2013), which has the medium and long-term risk background and ability of strong earthquake / large earthquake(Chang et al. 2014; Wen et al. 2013; Zhang et al. 2018), indicating that the seismic activity in northeast Yunnan province and its adjacent area where LFZ is located has entered a new active period(Fei et al. 2006). The characteristics of low $b$ value and low attenuation of Qiaojia earthquake sequence also show that the seismic risk in this area is still high(Fu et al. 2021). There are also references(Xu et al. 2014; Xu et al. 2015)that the LFZ is an active fault in the early Middle Pleistocene with weak fault activity. At present, there are still significant differences in understanding the activity and seismogenic capacity of the fault(Song et al. 2002; Wen et al. 2013; Zhang et al. 2018), mainly because no clear and direct geological evidence of fault activity has been published so far. There are high mountains and deep valleys along the Lianfeng fault, so the continuity and stability of Quaternary deposit are poor. However, there exist some river terraces of different ages and tributary 
alluvial fans. These units It can be compared in time and space, so can provide available space-time framework for constrain the nature and history of fault activity. It is one of the important ways to identify fault activity, and also the basis for evaluating regional seismic capacity and reasonably arranging seismic fortification. This paper aims to investigate the spatial and temporal distribution characteristics of Quaternary landform and deposit, and the recorded faulting characteristics of Qiaojia-Jinyang segment (QJS) in combination with regional survey data and remote sensing image interpretation, so as to provide geological basis for the assessment of activity and earthquake generating capacity of QJS during the Late Quaternary.

\section{Regional Background}

The LFZ began in Paleozoic and further developed in Mesozoic, with compression thrust as the main thrust and dextral strike slip as well(Wen et al. 2013). Its southwest end is connected with Ningnan-Huili Fault Zone; The northeast end is connected with Spacial Huayingshan Fault Zone. these three fault zones constitute the Generalized Huayingshan Fault Zone (GHFZ) with a length of more than $800 \mathrm{~km}$. GHFZ is the boundary fault between Daliangshan sub block and South China block, and is also the southeast boundary fault of Sichuan Basin (the Longmenshan Fault Zone, the seismogenic fault of 2008 Wenchuan strong earthquake, controls the northwest side of Sichuan Basin); Its characteristics are of great significance for understanding the regional seismogenic and seismogenic environment. Since Cenozoic, with the change of regional tectonic field, the ancient Huayingshan fault has been cut off by ZemuheXiaojiang fault and Mabian fault, forming a relatively independent LFZ(Sichuan Bureau Of Geology Resources 1991; Wen et al. 2013; Zhou et al. 1997), which, together with Zhaotong-Ludian Fault Zone, plays a role in absorbing and regulating the southeast movement component of Daliangshan subblock(Wen et al. 2013). The sub-block of Daliangshan in the west of LFZ is adjacent to the east side of Sichuan-Yunnan block, and its formation and evolution are mainly affected by the material migration of Tibetan Plateau (Fig. 1a). Mabian fault on the east side of the block is characterized by left lateral strike slip and compressional thrust(Zhang et al. 2005); The northern Anninghe fault, which located in west Anninghe-Zemuhe Fault Zone, is composed of east and west branches(He 2017; Tang et al. 1989; Tang et al. 1992). In the Late Quaternary, the activity is concentrated in the east branch fault, mainly left lateral strike slip(He and Ikeda 2007; Ran et al. 2008; Wen et al. 2013). Zemuhe Fault Zone is composed of five secondary shear active faults with left terrace plume(Yu 2010), which is characterized by multi-stage activity and is still very active since Late Pleistocene(Xie et al. 2017). The LFZ and the Huayingshan Fault Zone generalized intersect with the main stream of the Jinsha(upper Yangtze) River in the eastern segment of the Sichuan-Yunnan boundary, regionally, it is adjacent to many large reservoirs on the Jinsha River, such as Wudongde, Baihetan, Xiluodu, and Xiangjiaba. So its activity is of great significance in the evaluation of regional earthquake and seismogenic environment.

\section{Field Investigation And Dating Method}

Based on 1: 200000 geological map (Zhaotong sheet), DEM data and remote sensing image data, and the previous work, this study carried out field and lab investigation on the Qiaojia -Jinyang segment of the 
Jinsha River intersection zone of and along the lianfeng fault by combining point, line and surface. The main contents include: 1) terrace survey, mainly low terrace. The terraces near the southwest of Shanjiang township and Xiaoniulan village were mainly observed in terms of morphological characteristics, periods, types, distribution, profile structure and composition. The relative elevation of low terrace is mainly obtained from field estimation, while the relative elevation of high terrace is mainly obtained from DEM data. 2) The structural faulting in Quaternary deposits was investigated. This paper focuses on the investigation of structural fault characteristics recorded by terrace deposits within the Laojie east profile, the profile near confluence of Niulan river, the profile to southwest of Shanjiang township, and the profile to southwest of changpingzi, etc. 3) The filling of sand veins in Quaternary deposits was investigated. This paper focuses on the properties and characteristics of sand veins found in the southwest of Laojie and near Xiaoniulan River bridge. 4) Combined with the previous terrace research data, the terraces and fault phenomena are dated. It mainly includes OSL dating of typical terraces, faults and overlying strata in the southwest of Shanjiang township, Xiaoniulan Village and the southwest of Changpingzi (Fig. 1b).

The OSL sample collection method as follows: firstly, clean the surface layer of the profile, plug one end of the prepared stainless steel sample tube $(25 \mathrm{~cm}$ long and $5 \mathrm{~cm}$ in diameter) with light proof material to avoid light, and then hammer the sample tube into the layer to be tested; When the sediment is full, the stainless steel pipe shall be carefully taken out, and the two ends shall be immediately sealed with light proof material, and the two ends shall be tightly wrapped with adhesive tape; After the site number and sampling details are recorded, they are taken back to the laboratory for testing. The treatment process in lab is as follows: first, open the package in the dark room, remove the parts that may be exposed around, and keep the unpolluted and unexposed samples in the center for equivalent dose determination. $20 \mathrm{~g}$ of the sample which may be exposed was collected and dried for environmental dose rate determination. After the sample is processed, the purified quartz is paved on a small tray, each tray has about hundreds of quartz particles, and is made into a measuring piece for measurement. The equivalent dose test of the sample was completed on the automatic thermal / optical emission measurement system of Risoe DA20-C/D in Denmark. The natural equivalent dose (DE) (i.e. the ancient dose) of the sample was measured by single chip regeneration (SAR), and the coarse quartz mineral was used to test the sample, and the blue light was selected as the light source.

\section{Regional Quaternary Landform And Deposits}

The Jinsha River Valley is mainly characterized by alternate distribution of deep valleys and wide valleys. River terraces in the canyon segments are generally developed or poorly preserved, and are scattered on the valley slopes on both sides(Shen 1965). In this paper, the investigation of river terraces and related tributary alluvial fans in the study area is mainly limited to four terraces and below, and the main type is accumulation terrace, which is distributed intermittently along the river (Fig. 1b). The division of terraces is based on the existing research data of the Jinsha river terraces in the upper and lower reaches. The characteristics of each terrace are as follows: 
T1 terrace is mainly distributed along both banks of the Jinsha River, which is of sedimenary type and has dual structure of terrace. Taking the first terrace $1.2 \mathrm{~km}$ southwest of Shanjiang township as an example (Fig. 2a), the T1 profile is mainly composed of sand and gravel, with directional gravel and clear bedding of fine sand layer, with an overall inclination of about $30^{\circ}$, there are many positive cycle rhythmic layers from bottom to top. The top is covered with a thin layer of fine sand. T1 terrace is a narrow strip with height of $10 \sim 20 \mathrm{~m}$ above river level, which is the main construction land and farming area.

T2 terrace is mainly seen in Simaoping, Ganlanping, the southwest of Laojie, Xiaoniulan Village, Yaomituo Village and other places, with coarse composition. Taking the profile (Fig. 2b) exposed near the confluence of Xiaoniulan River, $4.7 \mathrm{~km}$ to the east of Laojie as an example, the lower part of the profile is medium coarse gravel accumulation without bedding; The middle part is composed of light yellow coarse silt and yellow green fine silt from bottom to top, with an overall inclination of about $25^{\circ}$. The internal bedding is undeveloped, which is interpreted as rapid accumulation; Oblique bedding can be seen in the upper gravel accumulation. The top floodplain sediments are not developed, which may be related to the later scouring. The height of T2 terrace is about $60 \sim 70 \mathrm{~m}$ above river level, and some segments are connected with the tributary alluvial fan in horizontal direction. The two can be compared in height above river level, sedimentary characteristics and formation age.

T3 terrace is mainly found in Laojie, Duiping Township, Xiaoniulan and Yaomituo Village. The profile exposed 500 meters to the east of Laojie platform (from the inner side of the road from Laojie to river side) shows that the profile is about $2.1 \mathrm{~m}$ high, which can be divided into three parts according to the grain size of the sediment (Fig. 2C): the upper part is fine sand layer with occasional gravel; The middle part is fine gravel accumulation; The lower part is medium coarse gravel accumulation. The height of T3 terrace is $120 \sim 150 \mathrm{~m}$ above river level. The continuity of terrace distribution is poor.

T4 terrace is mainly distributed in the east of Ganlanping, Laojie, south of Xiaoniulan, west of Duiping Township and other places. Taking the profile exposed in the front edge of Laojie platform as an example (Fig. 2d), the exposed height of the profile is about $1.8 \mathrm{~m}$. The profile has horizontal bedding from bottom to top, and the colors of the upper and lower parts are obviously different. The upper part is light yellow sand layer, and the lower part is soil red sand layer. T4 terrace often behave a flat surface with larger area and height of $180 \sim 190 \mathrm{~m}$ above river level. It is a relatively concentrated place for local residents' production and life.

The OSL dating results of the top of the first terrace in the southwest of Shanjiang Township is $7.1 \pm 8 \mathrm{ka}$ (Table 1); The OSL age at the top of the tributary alluvial fan corresponding to the second terrace of Xiaoniulan Village is $13.4 \pm 8 \mathrm{ka}$ (Table 1), which is similar to the terrace age of Qiaojia made by Li et al. (Li et al. 2016)(Table 1), indicating that the first and second river terraces at QJS were formed in the early and middle Holocene and Late Pleistocene (Fig. 3).

Table 1 Dating result of terraces deposits at QJS 


\begin{tabular}{|c|c|c|c|c|c|c|c|c|}
\hline $\begin{array}{l}\text { terrace/ } \\
\text { profile }\end{array}$ & $\begin{array}{l}U_{1} \\
\text { ug/g }\end{array}$ & $\begin{array}{l}\text { Th, } \\
\text { ug/g }\end{array}$ & $\begin{array}{l}\text { K, } \\
\text { ug/g }\end{array}$ & $\begin{array}{l}\text { measuring } \\
\text { technique }\end{array}$ & $\begin{array}{l}\text { grain } \\
\text { size, } \\
\mu \mathrm{m}\end{array}$ & $\begin{array}{l}\text { Environmental } \\
\text { dose rate, } G\end{array}$ & $\begin{array}{l}\text { Equivalent } \\
\text { dose,G }\end{array}$ & Age, ka \\
\hline $\mathrm{T} 1 / \mathrm{a}$ & 2.1 & 8.5 & 1.6 & SAR & 200.0 & $3.0 \pm 0.3$ & $21.5 \pm 2.8$ & $7.1 \pm 0.8$ \\
\hline $\mathrm{T} 2 / \mathrm{b}$ & 2.5 & 8.5 & 1.5 & SAR & 200.0 & $3.2 \pm 0.3$ & $42.9 \pm 2.7$ & $13.4 \pm 0.8$ \\
\hline$f$ & 2.0 & 8.5 & 1.6 & SAR & 200.0 & $3.0 \pm 0.3$ & $25.9 \pm 3.8$ & $8.7 \pm 1.3$ \\
\hline $\begin{array}{l}\text { F } \\
\text { (Overlying } \\
\text { sand } \\
\text { layer) }\end{array}$ & 1.9 & 11.3 & 1.6 & SAR & 200.0 & $3.0 \pm 0.3$ & $3.9 \pm 0.3$ & $1.3 \pm 0.1$ \\
\hline $\begin{array}{l}\text { Qiaojia } \\
\text { T2(Li et } \\
\text { al. 2016) }\end{array}$ & & & & ${ }^{14} \mathrm{C}$ & & & & 12.6 \\
\hline $\begin{array}{l}\text { Qiaojia } \\
\text { T1(Li et } \\
\text { al. 2016) }\end{array}$ & & & & ${ }^{14} \mathrm{C}$ & & & & 9.9 \\
\hline
\end{tabular}

\section{Characteristics Of Active Tectonics}

\subsection{Faulting characteristics}

At the intersection of LFZ and the Jinsha River, a large number of signs of tectonic activity are exposed in the Quaternary strata on both sides of the river. The surface deformation of fluvial terrace and the records of fault activity preserved in sediments are typical in the vicinity of Laojie in Qiaojia segment of the Jinsha River. The records of structural faults in each typical profile are as follows.

\subsubsection{The profile to east of Laojie}

The profile is located in the quarry on the third terrace on the east side of Laojie terrace, which is a manual excavation profile. At the outcrop of the fault, the profile is about $9 \mathrm{~m}$ high and can be divided into four layers (Fig. 4). The fault is developed in the gravel layer in the profile, and its strike is NW, and its occurrence is $45^{\circ} \angle 63^{\circ}$. The gravels are oriented along the fault surface, cemented by carbonate under the action of precipitation leaching and deposition, forming a dense thin layer with a thickness of about $40 \mathrm{~cm}$. The top boundary of the gravel layer on the profile shows the hanging wall thrust of the fault, which indicates that the fault has obvious thrust property.

\subsubsection{The profile near the confluence of Niulan river}

The profile is located at the second terrace $1.7 \mathrm{~km}$ southwest of Niulan River estuary on the right bank of the Jinsha River (Yunnan side), which is a manual excavation profile. The profile features are shown in Fig. 5a, and the structure is shown in Fig. $5 \mathrm{C}$. The strike of the fault is $\mathrm{NE}$, and the occurrence of the fault plane is $292^{\circ} \angle 78^{\circ}$. The fault contact relationship between the dolomite block in the middle of the profile 
and the gravel layer on both sides shows that the fault has the characteristics of flower like structure. According to the scratch marks on the dolomite, the fault is characterized by thrusting and dextral strike slip (Fig. 5b), and the sediment in the upper part of the dolomite is disturbed (Fig. 5C), indicating that the fault was active after the formation of the accumulation.

\subsubsection{The profile to southwest of Shanjiang Township}

The profile is located in the first terrace accumulation $1.2 \mathrm{~km}$ southwest of Shanjiang Township on the left bank of the Jinsha River (Fig.6). The exposed stratum of the profile is mainly gravel layer, which is arranged directionally and the bedding of fine sand layer is clear; There are many positive cycle rhythmic layers from bottom to top. The vertical fault distance is about $18 \mathrm{~cm}$. The strike of the fault is NE, the apparent dip angle is small, and the apparent dip is SW. It is a normal fault. The OSL age of the fine sand layer directly overlying the latest faulted formation is $7.1 \pm 8 \mathrm{ka}$ (Table1), indicating that the latest fault activity occurred in the early-middle Holocene.

\subsubsection{The profile to Southwest of Changpingzi}

The fault occurs in the accumulation of the second terrace $0.8 \mathrm{~km}$ southwest of Changpingzi, and is composed of a group of NE trending faults. The cap layer at the top of the profile is gravel. The middle and lower parts are mainly faulted strata, with fine sand layers on both sides; The middle gravel layer has coarse bedding, and its occurrence is nearly horizontal. There is little fine material in the gravel layer, which is supported by gravel, the south-east side thrusts over the fine-grained sediments(Fig. 7), the whole has extrusion characteristics. Several secondary faults in the profile have a fault core composed of oriented gravel (Fig. 7b, Fig. 7c), showing strong structural deformation; Precipitation leaches and deposits calcium carbonate along the profile, causing the profile to be lighter than both sides, is light gray. Most of the faults are steeply dipping, and the faulting surface tends to be opposite to the topographic slope; The one to the northwest is slightly gentler, with an occurrence of $344^{\circ} \angle 55^{\circ}$. The OSL samples collected from the fine-grained sediments of the faulty strata on the hanging wall of the fault are dated to $8.7 \pm 1.3 \mathrm{ka}$, and the OSL age of the overlying sandy sediments covering the faulty strata is $1.3 \pm 0.1 \mathrm{ka}$ (Table 1), which shows that the latest active time of the fault is from middle Holocene to Late Holocene.

\subsection{Characteristics of sand veins}

Sand veins are widely found in Quaternary deposits in the study area. Typical profiles are as follows:

\subsubsection{The profile to southwest of Laojie}

The sand vein is generally located in the inner part of LFZ. The exposed profile is formed by manual sand mining and is located in the sand gravel layer above the accumulation of the fourth stage platform in the southwest of Laojie (Fig. 8). The original sedimentary strata are slightly stratified. The veins are in various forms, mainly composed of fine sand, and the degree of cementation is higher than that of the strata on both sides. The width of vein body is about $3-10 \mathrm{~cm}$; The boundary is clear; Most of the veins cross the strata and intersect with the horizontal bedding at a large angle. The direction is variable, mainly in 
vertical or oblique direction (Fig. 8b). Most of the veins are cemented with $\mathrm{CaCO} 3$ caused by precipitation leaching, and the whole veins are white or light gray (Fig. 8d).

\subsubsection{The profile near Xiaoniulan River bridge}

The profile is located in the accumulation at the top of the second terrace near the Xiaoniulan River bridge (Fig. 9), and is distributed $800 \mathrm{~m}$ to the east of LFZ. It is a manual excavation profile. The height of the profile is about $40 \mathrm{~m}$. The profile deposits is more complex. The upper left part of the profile is gravelly sand deposit with small angle bedding and low gravel content. In the middle and upper part, there are sand and gravel deposits with well-developed oblique bedding and mixed accumulation, and the bedding is less and less obvious in the lower part. From the top to the bottom, a small amount of medium gravel, boulder and medium gravel accumulated, and almost horizontal bedding gravel bearing sand layer appeared at the bottom. Sand veins mainly exist in the upper part of the profile (Fig. 9a). The main features are that the veins are straight and slender, about $3 \sim 5 \mathrm{~cm}$ wide, with clear boundary. The sand veins are obliquely intersected with the primary bedding, and the apparent dip of the sand veins in the upper left and middle upper part of the profile is opposite. The color of the sand vein is lighter than that of the strata on both sides, which may be due to carbonate deposition caused by precipitation leaching..

The response of loose surface sediments to ground motions is mostly related to the liquidization mechanism(Li et al. 2021), and the liquefaction mechanisms with important sedimentary significance include liquefaction and fluidization( $\mathrm{Li}$ et al. 2021). There are many mechanisms of sediment liquefaction(Bridge and Demicco 2008): inverse density gradients is a common driving mechanism, and the liquefaction caused by this mechanism is mainly distributed along the interface (usually bedding) with the largest change of reverse density gradient, and is mainly characterized by curly bag shape; At present, there are many uncertainties about the contribution of fluid shear stress to sand liquefaction(Bridge and Demicco 2008). However, if such liquefaction exists, it will be distributed along the interface between fluid and sediment, and has obvious directionality. Under the action of gravity, the loose sediments will also liquefy when they are dumped along the slope (Allen 1985; Horowitz 2010; Owen 2010). This liquefaction is limited in the sliding boundary zone with a certain thickness, which has the properties of brittle and plastic transition, and has obvious shovel shaped characteristics on the profile. Fluidization is mainly related to the rising velocity of pore fluid. The strata of Laojie southwest profile $(\mathrm{g})$ and Xiaoniulan River bridge profile $(\mathrm{h})$ are mainly composed of sand and gravel, which are difficult to liquefy. The vein is mainly composed of fine sand, which is mainly interpenetrated in the middle and upper part of the sand gravel profile, and does not have the profile structure characteristics of the above mechanism. Therefore, the possible explanation mechanism is that the instantaneous vibration deformation caused by earthquake increases the pore water pressure in the sand body. When the pore water pressure rises to zero, the sand body is suspended in water, The total loss of strength and bearing capacity (Zhang et al. 2009), fluid and sediment escape rapidly upward through cracks or pipelines, sediment flows and migrates to form a series of sand veins. Based on the material composition and assemblage characteristics of the profile, the shape, occurrence and transgression characteristics of sand 
veins and their occurrence horizon, the authors believe that these sand veins are the products of post sedimentary seismic activities and one of the seismic records in Quaternary sediments.

\section{Discussion And Conclusion}

\subsection{Activity of LFZ}

As the southern boundary of Daliangshan sub-block, the activity of LFZ is closely related to the tectonic activity of Daliangshan sub-block. The Xianshuihe-Xiaojiang Fault Zone in the west is the east side street of the Sichuan -Yunnan rhombic block, and its sinistral movement rate is $15 \pm 5 \mathrm{~mm} / \mathrm{a}$ ( the north-west segment of Xianshui River ) to Zemuhe segment,is still about $15 \mathrm{~mm} / \mathrm{a}$, after crossing the LFZ, the sinistral velocity decreases to $10.4 \mathrm{~mm} / \mathrm{a}$. It is estimated that the compressive deformation absorbed by the southwest end of LFZ, which is nearly perpendicular to Xianshuihe- Xiaojiang Fault Zone, is about $5 \mathrm{~mm} / \mathrm{a}(\mathrm{Li}$ 1993). The Mabian-Yanjin Fault Zone on the east side of Daliangshan sub-block was left lateral strike slip thrust in Quaternary period, with a vertical slip rate of $0.8 \mathrm{~mm} / \mathrm{a}$ (Zhang et al. 2005). It indicates that there is a certain compression component in the northeast end of LFZ. It is necessary to point out that the left rotation rate of Anning segment of Xianshuihe-Xiaojiang Fault Zone is low, about 47mm/a(He et al. 2008; He and Ikeda 2007; Wen 2000; Wen et al. 2013), which means that some lefthanded components are explained by the left-hand activity of Daliangshan Fault Zone in the Daliangshan sub-block on the east side. Since the Holocene, the latter developed many earthquakes(Song et al. 2002; Zhang et al. 2018), and the latest active age was from 0 to 400 A.D.(He et al. 2008). The above facts show that the boundary and internal faults of the east and west sides of Daliangshan fault block are highly active. In contrast, the LFZ, as the SE trending "energy absorbing box" of the Daliangshan subblock, is considered to be in a locked state(Chang et al. 2014; Wen et al. 2013). Understanding the activity of LFZ is the key to evaluate its seismogenic ability. The characteristics of fault activity recorded by terrace accumulation in different periods along the Jinsha River show that Lianfeng fault has obvious compression and torsion characteristics in the main direction. The age of low terrace, structural fault and overlying strata dating results show that the latest tectonic activity is not earlier than the early - Middle Holocene. In addition, there is an increasing trend of small earthquakes in the study area recently. The latest Jinyang MS 3.6 earthquake on July 21, 2021 (focal depth: $17 \mathrm{~km}$, epicenter: $27.42 \mathrm{~N}, 103.08 \mathrm{E}$ ) fell on the Fault Zone, the is about $3 \mathrm{~km}$ away from Changpingzi profile.

\subsection{Fracture characteristics of LFZ}

Due to the anisotropy of lithosphere and the change of tectonic stress field in time and space, fault evolution can show extremely complex growth behavior(Agust 2013; Forsyth et al. 2009; Huntington and Klepeis 2018; Sh 2009). Although the structural fault profile observed in the field survey is located in the traditional LFZ in space, its occurrence and properties are not completely consistent with the overall trend and nature of the LFZ. For example, the faults found in the terrace deposits at the mouth of the Niulan River and the southwest of Changpingzi show that their strikes and fault dislocation properties are basically consistent with the fault occurrence (north-east strike) and properties (right-lateral compression 
twist) on a regional scale. While the trend of the Laojie east profile is almost orthogonal to the macroscopic trend of the fault, and the fault of the first terrace in the southwest of Shanjiang Township shows normal fault characteristics. No matter whether the ages and periods of these faults are the same or not, the fault array formed by the combination of secondary faults with different properties and occurrences indicates that the LFZ may have the characteristics of multi fault rupture. There may be several reasons for this fault spreading behavior. Firstly, the fractal characteristics of regional fault trace and earthquake distribution(Marrett and Allmendinger 1992; Schultz et al. 2008; Torabi et al. 2018; Walsh et al. 1991)determine that the fault behavior is rarely likely to be a single linear rupture. Secondly, the complex regional strata and deformation history lead to multi-scale anisotropy in physical and chemical properties of LFZ and its rocks. Thirdly, the strong river cutting in the study area makes the topography along the fault up to 2000-3000 m, which causes the high-frequency variation of stress field (especially the shallow surface) in time domain and spatial domain. In the process of fault extension, the latter two factors dominate the stress concentration and stress shadow in the structural zone to a great extent, which can easily induce the growth and connection of small faults, and then affect or control the regeneration, revival, migration or death of faults in the Fault Zone. An extreme example is the 2016 Kaikoura earthquake in northeastern South Island, New Zealand, involving the rupture of at least 12 major faults with different occurrence, slip direction and slip rate within $170 \mathrm{~km}$ (Hamling et al. 2017). It is worth noting that this kind of multi fault rupture behavior does not conform to many traditional assumptions that the nature, characteristics and degree of earthquake rupture are controlled by fault segmentation(Chen et al. 2018; Zhang et al. 2012). How to re evaluate in earthquake disaster model(Hamling et al. 2017) should be paid enough attention.

\subsection{Main conclusions}

The geomorphologic, sedimentary, structural and geochronological investigations of the Jinsha River terraces at QJS shows that the first and second terraces (with height of $10 \sim 20 \mathrm{~m}$ and $60 \sim 70 \mathrm{~m}$, respectively, above river level) of the Jinsha River were formed in the middle Holocene and Late Pleistocene, indicating that the river at QJS was cut down strongly since Late Pleistocene; The geochronological constraints on the tectonic faulting in terrace deposits indicate that the latest active age of the QJS is not earlier than the early-middle Holocene. The analysis of the profile characteristics of sand vein filling in terrace sediments indicates the cause of ground motion, and implying that LFZ has been strong active since Quaternary. In addition, the rupture behavior of QJS may have the characteristics of multi fault rupture, which should be paid enough attention to in earthquake damage evaluation.

\section{Declarations}

\section{Dear Editor,}

We the undersigned declare that this manuscript entitled "Geomorphological and sedimentary records of Late Quaternary activities of Qiaojia-Jinyang segment of Lianfeng fault zone, Southwest China" is original, has not been published before and is not currently being considered for publication elsewhere. 
We confirm that the manuscript has been read and approved by all named authors and that there are no other persons who satisfied the criteria for authorship but are not listed. We further confirm that the order of authors listed in the manuscript has been approved by all of us. We understand that the Corresponding Author is the sole contact for the Editorial process. He is responsible for communicating with the other authors about progress, submissions of revisions and final approval of proofs.

Sincerely

Authors

2021.8.7

Funding: This work was supported by the Key projects of basic scientific research business of central public welfare research institutes (grant number ZDJ2019-14); and the project of National Natural Science Foundation of China (grant number 41471002).

Authors' contributions: Youpeng Wang: Investigation, Data processing, Writing- Original draft preparation.Dewen Li: Investigation, Supervision, Writing- Original draft preparation.

Geomorphological and sedimentary records of Late Quaternary activities of Qiaojia-Jinyang segment of Lianfeng Fault Zone, Southwest China

Youpeng Wang ${ }^{\mathrm{a}, \mathrm{b}, \mathrm{c}}$, Dewen $\mathrm{Li} \mathrm{i}^{\mathrm{a}, \mathrm{b},{ }^{*}}$

a. National Institute of Natural Hazards, Ministry of Emergence Management, Beijing, 100085, China

b. Key Laboratory of Crustal Dynamics, China Eartquake Administration, Beijing, 100085 China

c. Wuhai Emergency Management Bureau, Wuhai, Inner Mogolia, 016000, China

Acknowledgements: This work was supported by the Key projects of basic scientific research business of central public welfare research institutes (grant number ZDJ2019-14); and the project of National Natural Science Foundation of China (grant number 41471002). Master student Wang Jinpeng participated in surveys and of regional landform and sediments. The field investigation received strong support and help from the Duxiang Expressway Project Department, China International Engineering Consulting Corporation. The optical luminescence (OSL) dating was completed with the assistance of the Chronology Laboratory of Shandong Seismological Bureau. The author would like to express his deep gratitude to the above-mentioned units and related personnel.

\section{References}

1. Agust G (2013). Great challenges in structural geology and tectonics. Frontiers in Earth Science 1, 19. 
2. Allen P A (1985). Hummocky cross-stratification is not produced purely under progressive gravity waves. Nature 313, 562-564.

3. Bridge J, Demicco R (2008). Earth Surface Processes, Landforms and Sediment Deposits. CambridgeखUK, Cambridge University Press.

4. Chang Z, Zhou R, An X, Chen Y, Zhou Q, Li J (2014). The late quaternary activity of Zhaotong-Ludian Fault and its tectonic significance (in chinese). Seismology and Egology 36, 1260-1279.

5. Chen L, Li Y, Gao S (2018). Multi-fault rupture behavior and prediction of major earthquakes (in chinese). Recent Developments in World Seismology, 24.

6. Davies J N, Sykes L R, House L, Jacob K H (1981). Shumagin Seismic Gap, Alaska Peninsula: History of great earthquakes, tectonic setting, and evidence for high seismic potential. Journal of Geophysical Research Solid Earth 86, 3821-3855.

7. Fei M, Yu Q, Xie Y, Lu Y, Shao W (2006). Analysis on the Ludian M5.6 earthquake disaster 区in chinese区. Journal of Seismological Research 29, 87-91.

8. Forsyth D W, Lay T, Aster R C, Romanowicz B (2009). Grand Challenges for Seismology. EOS, Transactions American Geophysical Union.

9. Fu Z, Jiang C, Yin F, Zhang L, Shen X, Fang L, Li C, Zhang X, Xu L (2021). Preliminary Report on the 18 May 2020 Ms 5.0 Qiaojia Earthquake, Yunnan, China. Seismol Res Lett 92, 2122-2133.

10. Gaudemer Y, Tapponnier P, Meyer B, Peltzer G, Guo S, Chen Z, Dai H, Cifuentes I (1995). Partitioning of crustal slip between linked, active faults in the eastern Qilian Shan, and evidence for a major seismic gap, the'Tianzhu gap', on the western Haiyuan Fault, Gansu (China). Geophys J Int, 599-645.

11. Hamling I J, Hreinsdóttir S, Clark K, Elliott J, Liang C, Fielding E, Litchfield N, Villamor P, Wallace L, Wright T J (2017). Complex multifault rupture during the 2016 Mw 7.8 Kaikōura earthquake, New Zealand. Science 356, m7194.

12. He H, Ikeda Y (2007). Faulting on the Anninghe fault zone, southwest China in late quaternary and its

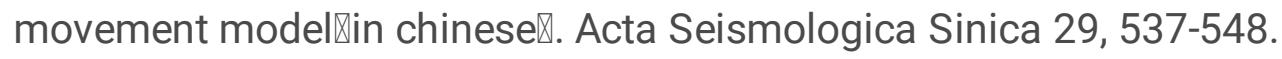

13. He H, Ikeda Y, He Y, Togo M, Chen J, Chen C, Tachikara M, Echigo T, Okada S (2008). Newly born Daliangshan fault zone-the cutting and straightening of the middle section of the XianshuiheXiaojiang fault system (in chinese). Science in China(Series D $\mathbb{3 8}$, 564-574.

14. He J (2017). Study on geological disasters induced by Mianning section of Anning River fault zone based on remote sensing technology (in chinese), AnHui JianZhu university.

15. Horowitz D H (2010). Geometry and origin of large-scale deformation structures in some ancient wind-blown sand deposits. Sedimentology 29, 155-180.

16. Huntington K W, Klepeis K A (2018). Challenges and opportunities for research in tectonics: Understanding deformation and the processes that link Earth systems, from geologic time to human time. A community vision document submitted to the U.S. National Science Foundation.

17. Li D, Li L, Ma B, Zhang J (2021). Characteristics of lake sediment response to earthquakes and the reconstruction of paleoseismic sequences $囚$ in chinese囚. Earth Science Frontiers 28, 232-245. 
18. Li P (1993). Xianshuihe Xiaojiang fault zone (in chinese). Beijing, Seismological Press.

19. Li T T, Pei X J, Huang R Q, Wang S (2016). Ancient landslides and contributions to Qiaojia basin's deposits. J Mt Sci-Engl, 1281-1286.

20. Marrett R, Allmendinger R W (1992). Amount of extension on \"small\" faults: An example from the Viking graben. Geology 20, 47.

21. Owen G (2010). Experimental soft-sediment deformation: Structures formed by the liquefaction of unconsolidated sands and some ancient examples. Sedimentology 43, 279-293.

22. Perez O J, Jacob K H (1980). Tectonic model and seismic potential of the eastern Gulf of Alaska and Yakataga seismic gap. Journal of Geophysical Research Solid Earth 85, 7132-7150.

23. Ran Y, Chen L, Cheng J, Gong H (2008). Late quaternary surface deformation and strong earthquake rupture behavior of the Anninghe fault north of Mianning. Science in China(Series D『38, 543-554.

24. Ruddiman W F (1997). Tectonic uplift and climate change. New York, Plenum Press.

25. Schultz R A, Soliva R, Fossen H, Okubo C H, Reeves D M (2008). Dependence of displacement-length scaling relations for fractures and deformation bands on the volumetric changes across them. $J$ Struct Geol 30, 1405-1411.

26. Sh W (2009). SeiSmological grand challengeS in UnderStanding earth ' S dynamic SyStemS, Report to the National Science Foundation, IRIS Consortium, p. 76.

27. Shen $Y$ (1965). Valley landforms of the upper Yangtze River囚in chinese囚. Beijing, Science Press.

28. Sichuan Bureau Of Geology Resources (1991). Regional geology of Sichuan province『in chinese邓. Beijing, Geological Publishing House.

29. Song F, Li R, Xu X (2002). Preliminary results of the investigation of Paleo-earthquakes along the Daliangshan fault zone, Sichuan province, China. Seismology and Geology 24, 27-34.

30. Sykes L R (1971). Aftershock Zones of Great Earthquakes, Seismicity Gaps, and Earthquake Prediction for Alaska and the Aleutians. Journal of Geophysical Research 76, 8021-8041.

31. Tang R, Huang Z, Wen D, Xia D (1989). Discussion on the segmentation and seismicity of the new activity in the Anning river fault zone区in chinese区. Journal of Seismological Research 12, 337-347.

32. Tang R, Qian H, Huang Z, Wen D, Wu X, Cai C, Tian H (1992). Segmentation characteristics of the

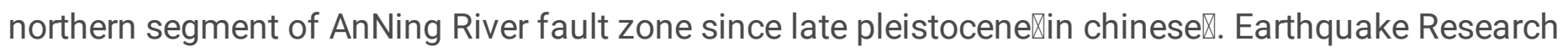
in China 8, 60-68.

33. Torabi A, Alaei B, Libak A (2018). Normal fault 3D geometry and displacement revisited: Insights from faults in the Norwegian Barents Sea. Mar Petrol Geol 99.

34. Walsh J, Watterson J, Yielding G (1991). The importance of small-scale faulting in regional extension. Nature 351, 391-393.

35. Wen X (2000). Character of rupture segmentation of the Xianshuihe-Anninghe-Zemuhe fault zone,western Sichuan (in chinese). Seismology and Egology 22, 239-249.

36. Wen X, Du F, Yi G, Long F, Fan J, Yang P, Xiong R, Liu X, Liu Q (2013). Earthquake potential of the

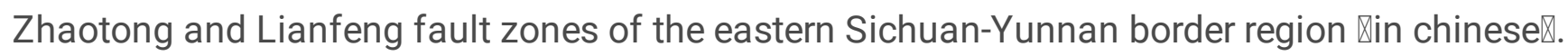


Chinese Journal of Geophysics 56, 3361-3372.

37. Xie J, Feng W, Yang S, Li C, Hu Y, Wang Q (2017). Active characteristics and geohazard of Zemuhe fault and their influence on morphological evolution in Ezhang River (in chinese). Journal of Engineering Geology 25, 772-783.

38. Xu X, Jiang G, Yu G, Wu X, Zhang J, Li X (2014). Discussion on seismogenic fault of the Ludian Ms6. 5 earthquake and attribution (in chinese). Chinese Journal of Geophysics 57, 3060-3068.

39. Xu X, Xu C, Li X (2015). Characteristics of surface rupture zone of Ludian earthquake in southeastern Qinghai-Tibet Plateau, Annual Meeting of Chinese Geoscience Union (CGU).

40. Yu J (2010). Fault activity rate about typical sections of Zemuhe fault zone 『in chinese区, Institute of Earthquake Forecasting, CEA.

41. Zhang $\mathrm{H}$, Chen J, Ge Z (2012). Multi-fault rupture and successive triggering during the $2012 \mathrm{Mw} 8.6$ Sumatra offshore earthquake. Geophys Res Lett 39, 22305.

42. Zhang S, Nie G, Liu X, Ren J, Su G (2005). Kinematical and structural patterns of Yingjing-MabianYanjin thrust fault zone, southeast of Tibetan Plateau, and its segmentation from earthquakes囚in chinese区. Seismology and Egology 27, 221-233.

43. Zhang W, Li W, Tian Q, Xu Y, Wang L (2018). Quaternary activity characteristics of the Lianfeng and Zhaotong Fault Zones based on deformation of the Broad Valley Surfaces of the Niulan River (in chinese). Earthquake 38, 22-36.

44. Zhang Z, Wang S, Wang L, Huang R, Xu Q, Tao L (2009). Principles of engineering geological analysis (in chinese). Beijing, Seismological Press.

45. Zhou R, Tang R, Qian H, Wen D, Ma S, He Y, Pu X (1997). Nonlinear dynamic response for elastic thin shallow shell on elestic half space subject to horizontal seismic force with rayleigh damping खin chinese $\rrbracket$. Journal of Seismological Research 20, 316-322.

\section{Figures}




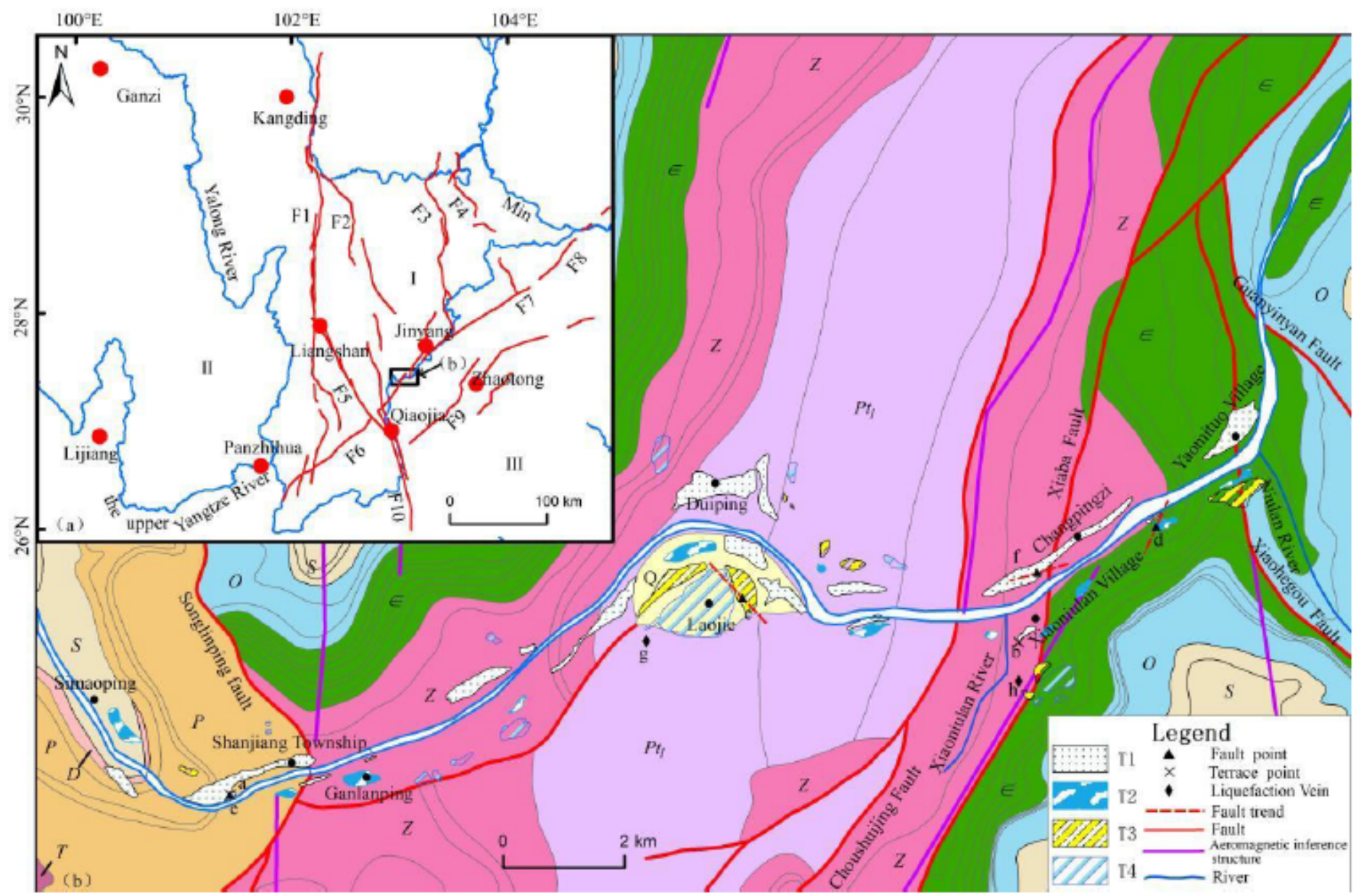

\section{Figure 1}

Regional tectonics and Quaternary terraces distribution in the study area. Note: (a) Regional tectonic characteristics. $\nabla$ is the Daliangshan sub-block; $\nabla$ is the Sichuan-Yunnan block; $\nabla$ is the South China block. Main fault: F1 Anninghe fault, F2 Daliangshan fault, F3 Ebian-Jinyang fault, F4 Mabian faut, F5 Zemuhe fault, F6 Ninghui fault, F7 Lianfeng fault, F8 Huayingshan fault, F9 Ludian-Zhaotong fault, F10 the north of Xiaojiang fault. (b) Distribution of terraces along the Jinsha River in the southwestern segment of the LFZ. Main investigation points: a, Southwest of Shanjiang Township; b, Xiaoniulan river Village; $c$, East of Laojie; d, the confluence of Niulan River; e, Southwest of Shanjiang Township; f, Southwest of Changpingzi; g, Southwest of Laojie; h, Xiaoniulan River Bridge. Q-Quaternary alluvium; T-Triassic greywacke formation; P-Permian carbonate formation; D-Devonian iron rock formation; S-Silurian siltstone mudstone formation and argillaceous limestone formation; O-Ordovician carbonatite formation

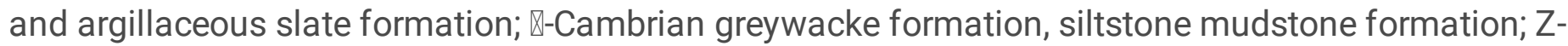
Sinian complex glutenite formation and dolomitic limestone-dolomite formation; Pt1-Proterozoic metamorphic rock formation. 

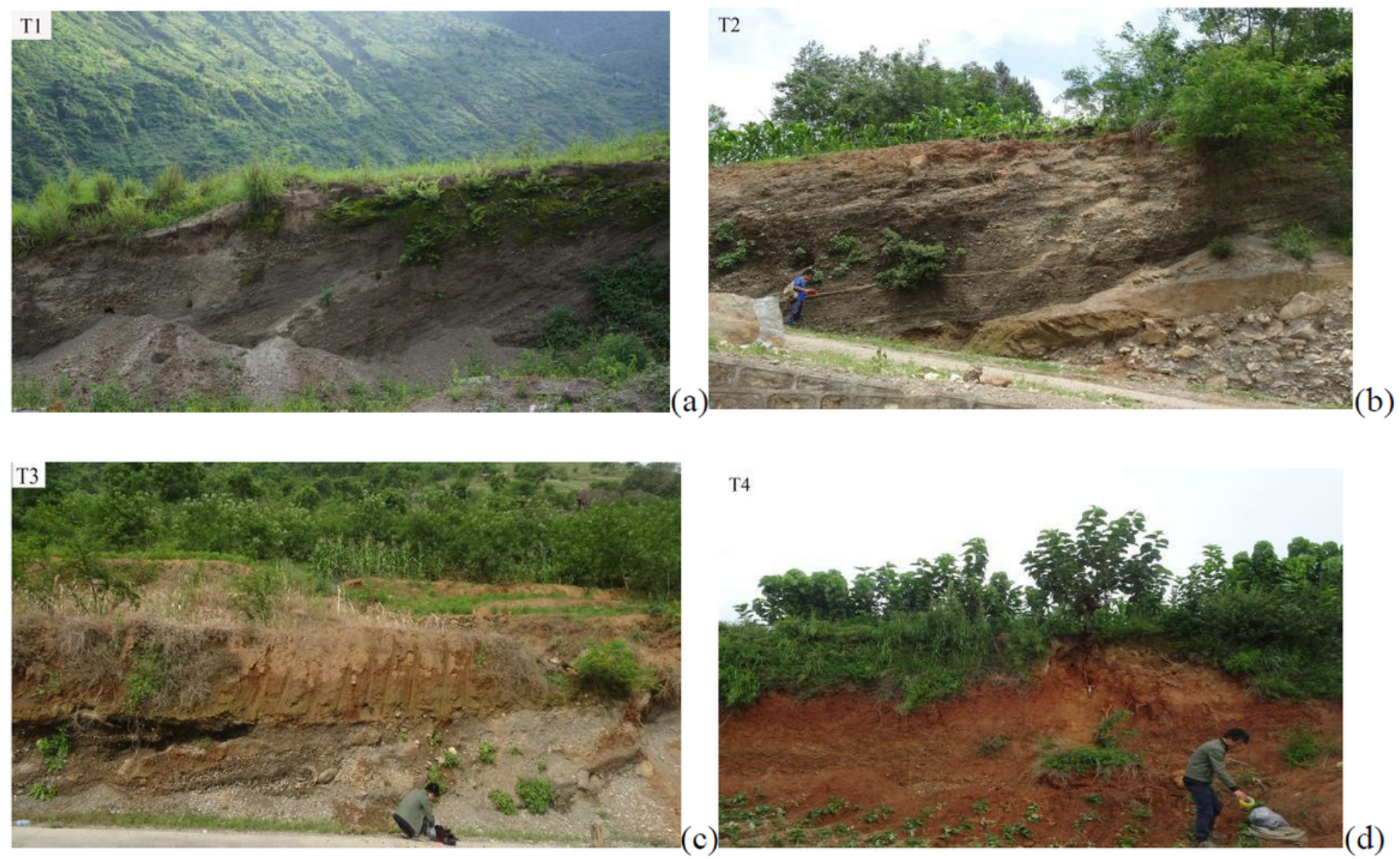

\section{Figure 2}

The geomorphic and sedimentary features of river terraces at QJS, the Jinsha River. Note: a,The first terrace T1 in the southwest of Shanjiang Township, The height of the profile is about $4 \mathrm{~m}$, lens direction SW; $b$, The second terrace T2 near xiaoniulan village , lens direction NE; c, The third terrace T3 near Laojie, lens direction NW; d, The fourth terrace T4 near Laojie, lens direction NW. 


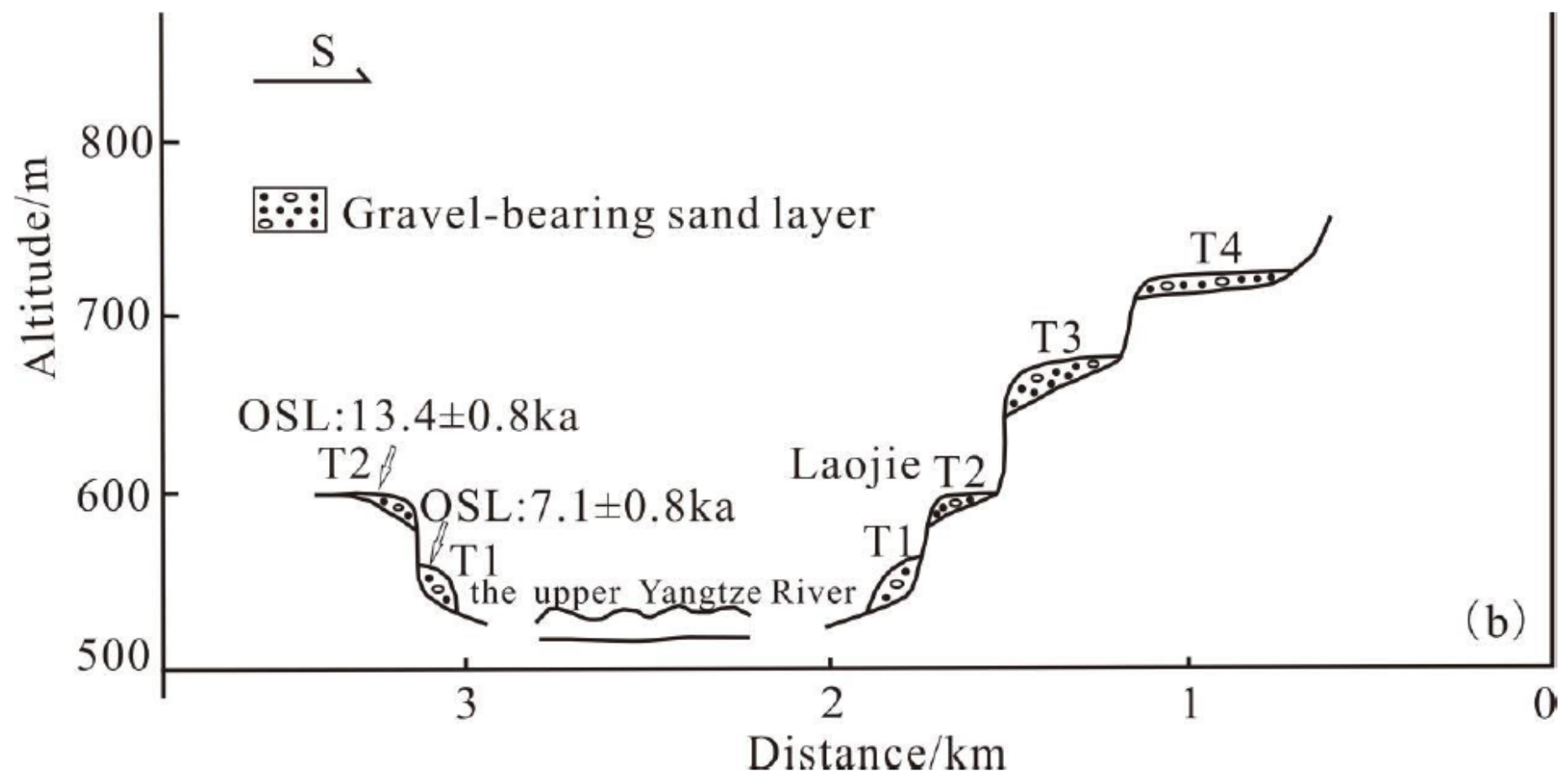

Figure 3

Terrace sequence near Laojie, the Jinsha River.
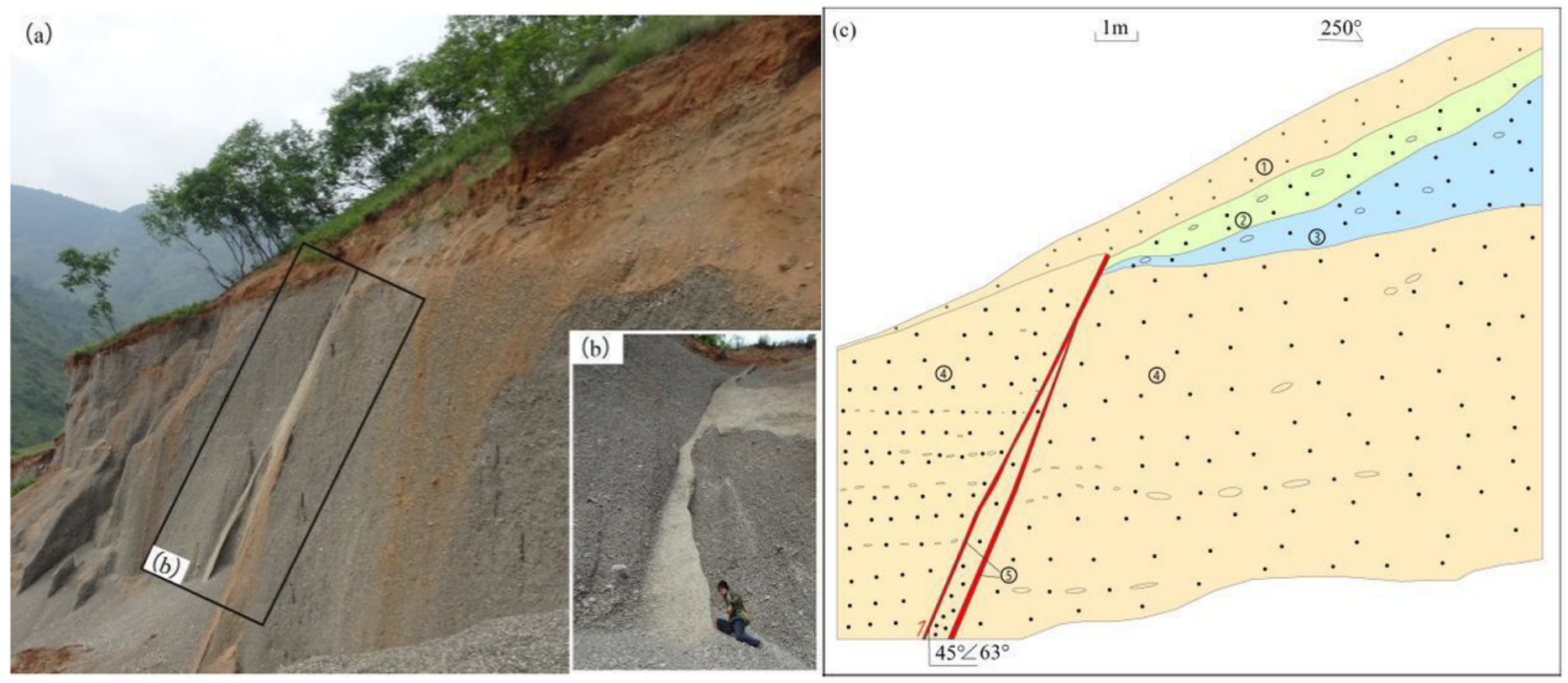

\section{Figure 4}

Faulting features within the terrace deposits to east of Laojie Note: a, Characteristics of fault profile in east of Laojie,lens direction SW ; $b$, The hardened layer developed along the fault is cemented by calcium carbonate leached and deposited along the fault plane by atmospheric precipitation; c, the profile of fault, $\nabla$ Soil red sand overburden, The surface is well covered with less sand and stone, and the thickness 
gradually thickens from southeast to northwest, and the thickness of the fault is about $1 \mathrm{~m}$; $\otimes$ and $\otimes$ are grayish white sand gravel layer and yellowish sand gravel layer, and the gravel content increases gradually; $\otimes$ is the main part of the profile, about $8 \mathrm{~m}$ thick as a gray-white sandy gravel layer, dominated by fine gravel, with a small amount of sand, with bedding; $₫$ The hardened layer formed by leaching and cementation along faulted surfaces.
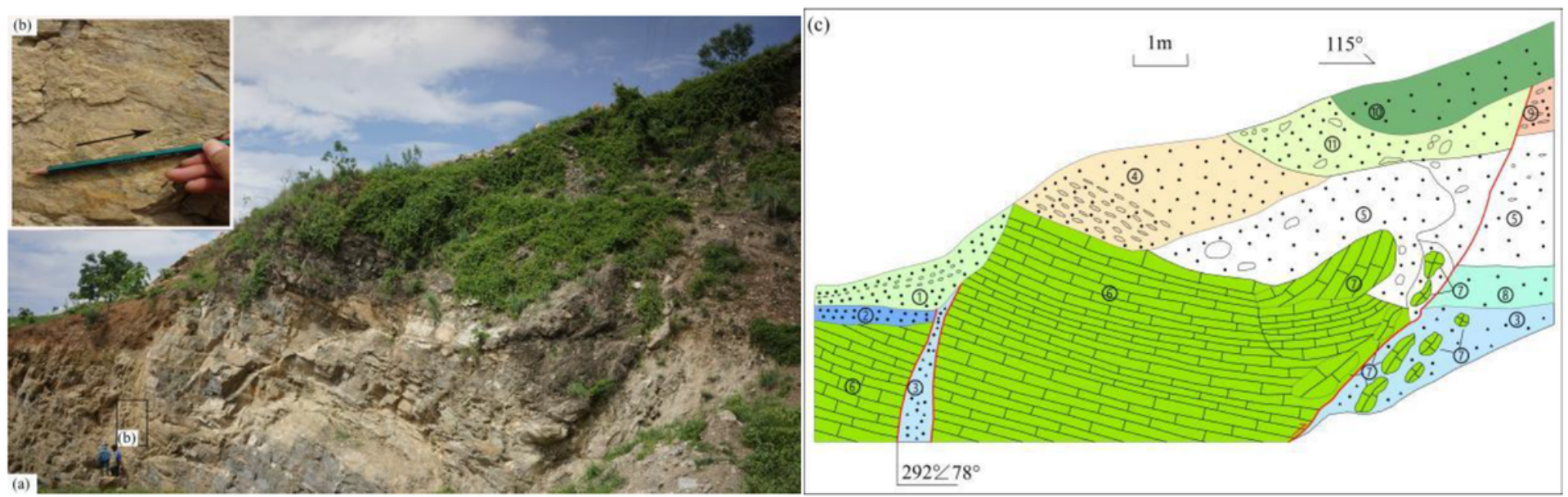

\section{Figure 5}

The faulting feature of the second terrace near the Niulan River mouth Note: a, Faulting profile near the Niulan River confluence, lens direction is NE. b, Details of fault striations. c, The profile of fault, $\mathbb{\nabla}$ is the dark-red humus soil layer, $\varangle$ Light gray sand layer, $\nabla$ Fault fracture zone, $\varangle$ Gravel layer, $\varangle$ Gravelly sandy soil layer, $\otimes$ Dolomite, $\otimes$ Dolomite lens, $\otimes$ Sand layer, $\otimes$ Sandy gravel layer, $\otimes$ Fine sand accumulation, $\otimes$ Gravel bearing accumulation.

(a)
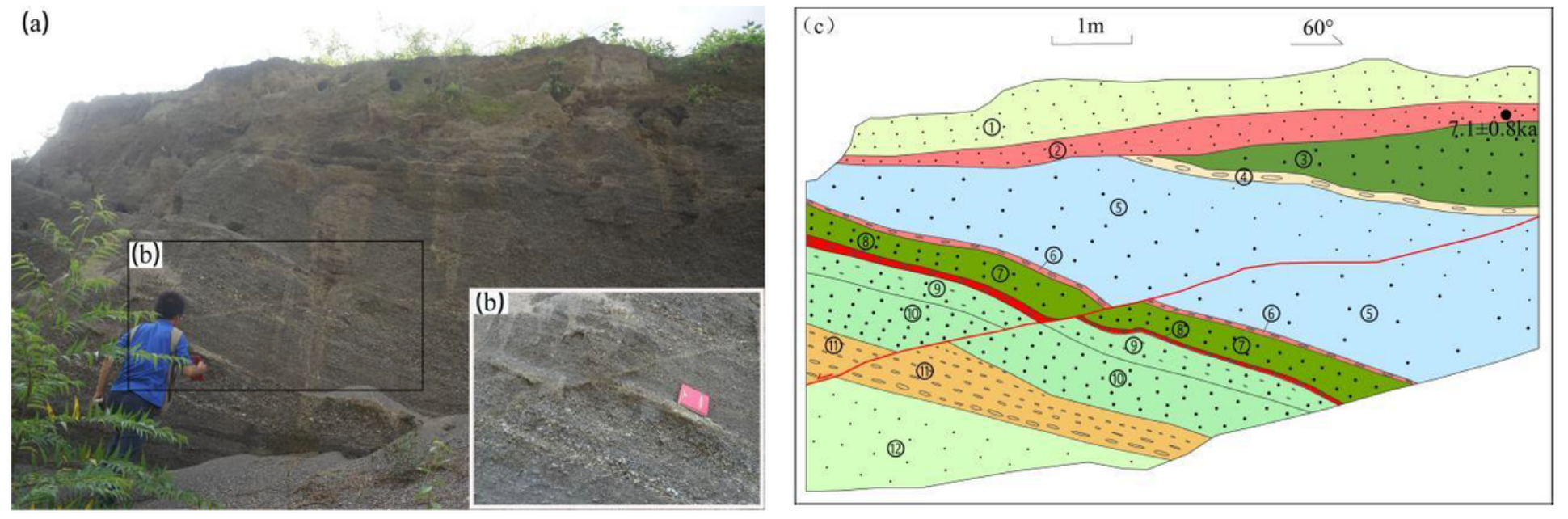

\section{Figure 6}

Faulting feature within first terrace deposit to southwest of Shanjiang Township Note: a, Characteristics of fault in the southwest of Shanjiang Township, lens direction SW. b, Fault details. c, The profile of fault,

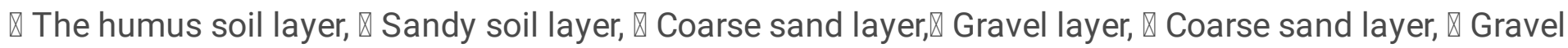


layer, $\otimes$ Coarse sand layer, $₫$ Gravel layer, $\otimes$ Gravel bearing coarse sand layer, $₫$ Coarse sand layer, $\bowtie$ Coarse

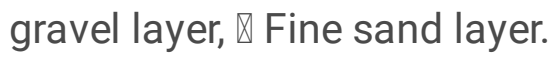
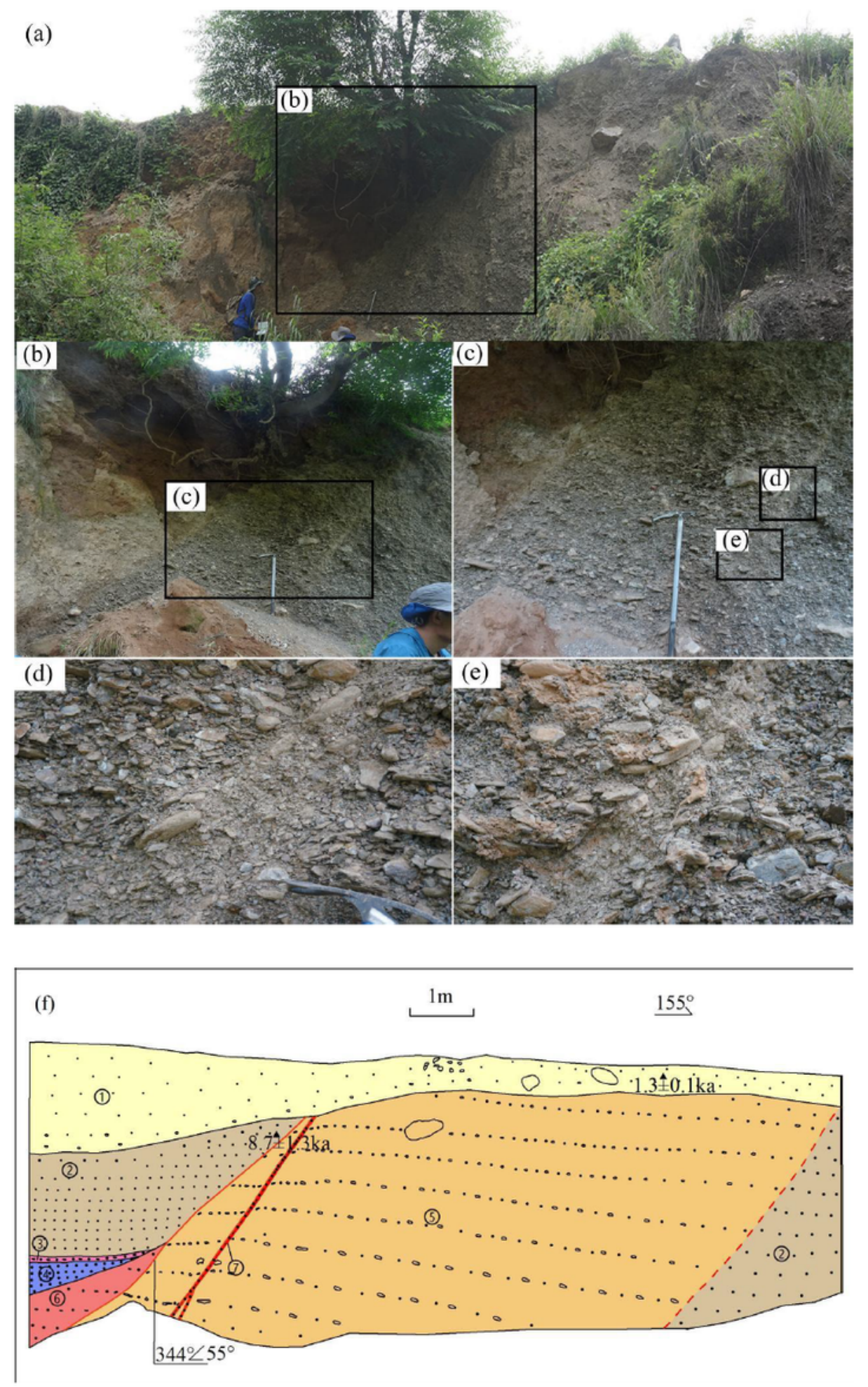

\section{Figure 7}

Faulting feature within deposit of the second terrace near Changpingzi Village at left bank of Jinsha River Note: $a$, The characteristics of the fault profile, lens direction NE; b, Fault details; c, Gravels arranged locally along fault plane; $d$ and e, Detail of the fault; $f$, Fault profile, $\otimes$ Gravel sand overburden, $\otimes$ Red clayed 
fine sand layer, $₫$ Grayish white sand gravel layer, $\otimes$ Yellowish brown coarse sand layer, $₫$ Gray gravel layer, $\otimes$ Light gray fault core, $\otimes$ Yellowish brown gravelly coarse sand layer. The red dotted line, on the right in Fig. $7 f$, is the fault plane inferred from the sediments.

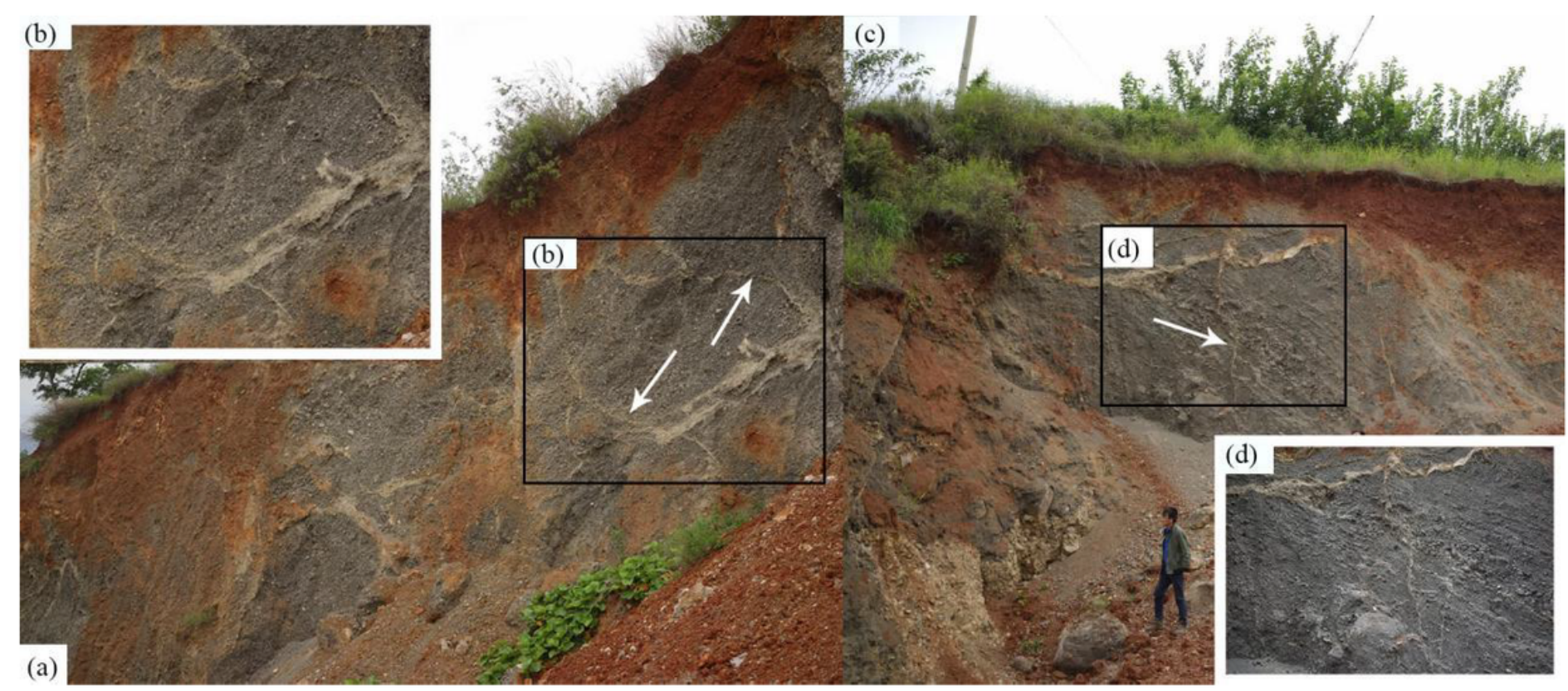

\section{Figure 8}

Sand veins within terrace deposit to southwest of Laojie Note: a and c, characteristics of sand veins exposed in terrace sediments in southwest Laojie,lens direction NW; b, Details of sand vein,the position indicated by the arrow is sand vein; $d$, The veins are white ribbons cemented by calcium carbonate. 

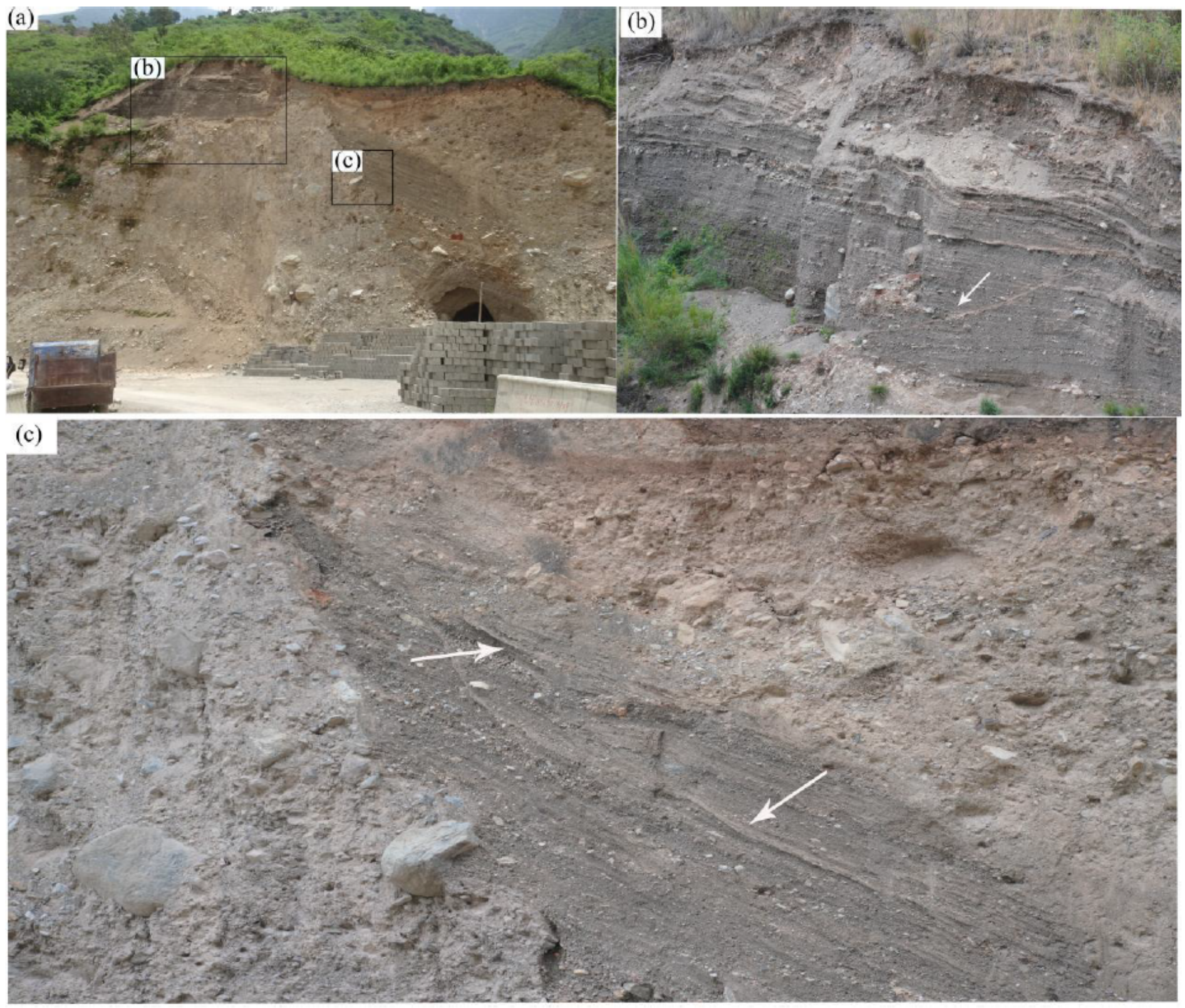

\section{Figure 9}

The feature of sand veins in the terrace deposit, near the Xiaoniulan River bridge Note: a, the characteristics of the profile in Xiaoniulan River bridge, lens direction NW, the profile is about 44m; $b$, Details of sand veins in the upper left part of the profile; $c$, Details of sand veins in the middle and upper profile of the profile; The arrow points to the sand vein. 